\title{
ACRL in Las Vegas ACRL programs at the ALA Annual Conference
}

\section{Financial literacy ... in Las Vegas}

Gambling in Las Vegas is a mainstay. A conversation about financial literacy, however, was entirely new when 2013-14 ACRL President Trevor A. Dawes decided to make this the focus of his presidential initiative and host "Financial Literacy at Your Library." The program featured The Washington Post syndicated columnist Michelle Singletary and David Eisler, president of Ferris State University, who called on librarians to get involved.

"This is one of the greatest issues for this generation. I have three children, and I want them to get this because. . . I want them to

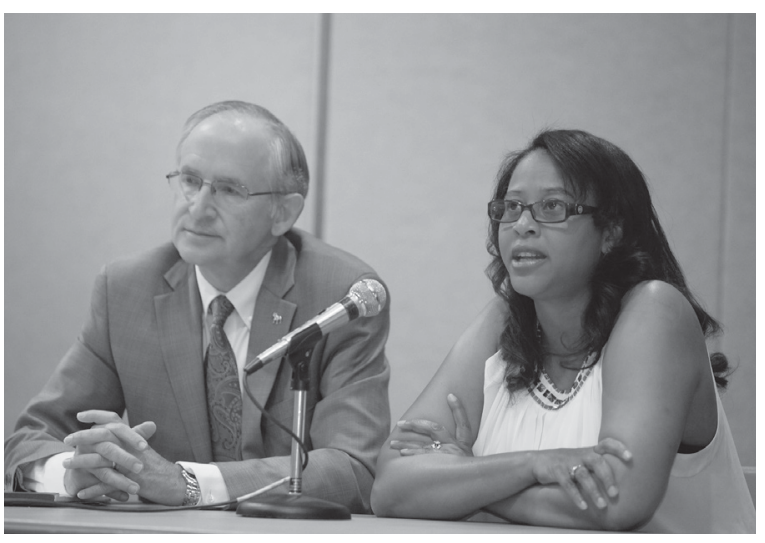

ACRL President's Program speakers (left to right): David Eisler and Michelle Singletary. all need someone to lean on. And for college students, this could be a librarian.

"One event won't do it," she said. "You have to change people's minds before you change their behavior." She encouraged the audience to "be entertaining, engaging, and enlightening" in their programming.

Eisler echoed Singletary's sentiments. "It goes beyond student debt," he said. Conversations about graduate school costs, graduating earlier as opposed to taking unnecessary classes, and finding ways to lower textbook costs are all a part of the equation. Financial literacy "is not a library problem, a president's problem, a student's problem," he continued. "It's everyone's problem." Librarians, however, are uniquely positioned to tackle the issue, and "they should," concluded Singletary.

To read more about the program and find best practices for financial literacy in libraries, visit http://goo.gl/w0BzYH or contact Cochairs of the President's Program, Deb Malone (debbie.malone@desales.edu) or Adi Redzic (adi@iomechallenge.org)._Adi Redzic, iOme Challenge,adi@iomechallenge.org 


\section{ACRL/AASL Interdivisional Committee on Information Literacy}

The ACRL/AASL Interdivisional Committee on Information Literacy sponsored "Common Core State Standards (CCSS) and General Education: Information Literacy Connects the Dots." Jennifer Fabbi, moderator; William Speer; Cyndi Giorgis (all of University of Nevada-Las Vegas); and Ken Stewart (Blue Valley High School in Stilwell, Kansas) explored connections between information literacy, CCSS assessments, and teacher preparation.

Speer discussed changes in assessment under the CCSS. Assessments measure the student's growth as "a problem poser" who can organize an argument, evaluate sources, and construct an evidence-based essay. Students not only answer the question and show how they found the answer, but they also interpret the significance of the problem. Each test result has a built-in diagnostic to identify students who need help while they are still in high school.

Giorgis asserted that the CCSS's increased emphasis on problem formulation and solution requires a change in teacher preparation. Teacher preparation programs must recruit for diversity; alter discipline courses; and "identify, nurture, and sustain high-quality field experiences." Teachers seeking school library endorsement should also adopt a proactive role in student learning and learn how to support student acquisition of information literacy.

Stewart described his practice as a high school librarian who integrates library instruction with classroom instruction by initiating contact with classroom teachers. Using the district's informal scope and sequence guide for information literacy acquisition, Stewart engages teachers in "College Readiness Dialogues" to demonstrate student need for explicit information literacy instruction.

Fabbi summarized the session's "takeaways":

- Educators should "know what is going on with implementation of CCSS and assessments in their state and locally."

- Educators should open channels of communication, sharing examples of assignments.
High school teachers and librarians can learn about college expectations by experiencing an "in their shoes" activity.

- Librarians should "build assignments with faculty," because "we need to teach [students] what to do with information."-Mary Keeling, Newport News Public Schools, mary. keeling@nn.k12.va.us

\section{Supporting community transformation}

"Supporting Community Transformation: Becoming a Community-Engaged Academic Library," cosponsored by the Education and Behavioral Sciences Section and the Anthropology and Sociology Section, provided examples of how academic libraries could become more involved in the community. Patrick Griffis (University of Nevada-Las Vegas [UNLV]) began the program stating community engagement should become the third mission of academic libraries because it complements teaching and learning. He provided various examples of how this could be accomplished, such as offering research workshops and embedding librarians within local small business development centers.

Griffis developed a series of free workshops for local businesses owners and entrepreneurs called "Business by the Book" (www.library.unlv.edu/about/university -libraries-business-book-workshop-series). The workshops provided attendees an outlet to learn about the resources available at UNLV as well as a chance to network with other professionals. Griffis then introduced Lora Hendrickson (Radioactive Productions), who talked about how the workshops allowed her to connect and network with other Las Vegas businesses in order to expand her clientele.

For the second half of the program, Claytee White (Oral History Research Center at UNLV), discussed how her department collaborated with the local PBS station to create the "Documenting the African American Experience in Las Vegas" portal (http://digital. library.unlv.edu/aae).

By engaging the African American community in Las Vegas through town hall meetings and word of mouth, the project became 
popular and successful. As a result, UNLV received donations of photographs and offers to help identify people and places in the photographs.

White and her staff also went into the community to collect and record audio and video of African Americans telling stories about their experiences living in Las Vegas. White demonstrated how this was done by conducting an oral history interview with Jarmilla McMillan-Arnold (Historic Preservation Commission, City of Las Vegas).
For example, mirror neurons tie together what you know how to do with what you observe others doing. Undergraduates have articulated this when they say they go to a particularly quiet library to "up my game" when studying. What are other ways in which patrons interacting with library collections and spaces are influential?

Libraries are a functional type of building and yet are also representational with a symbolic language. There is a fear that symbolic language can be sidelined for the

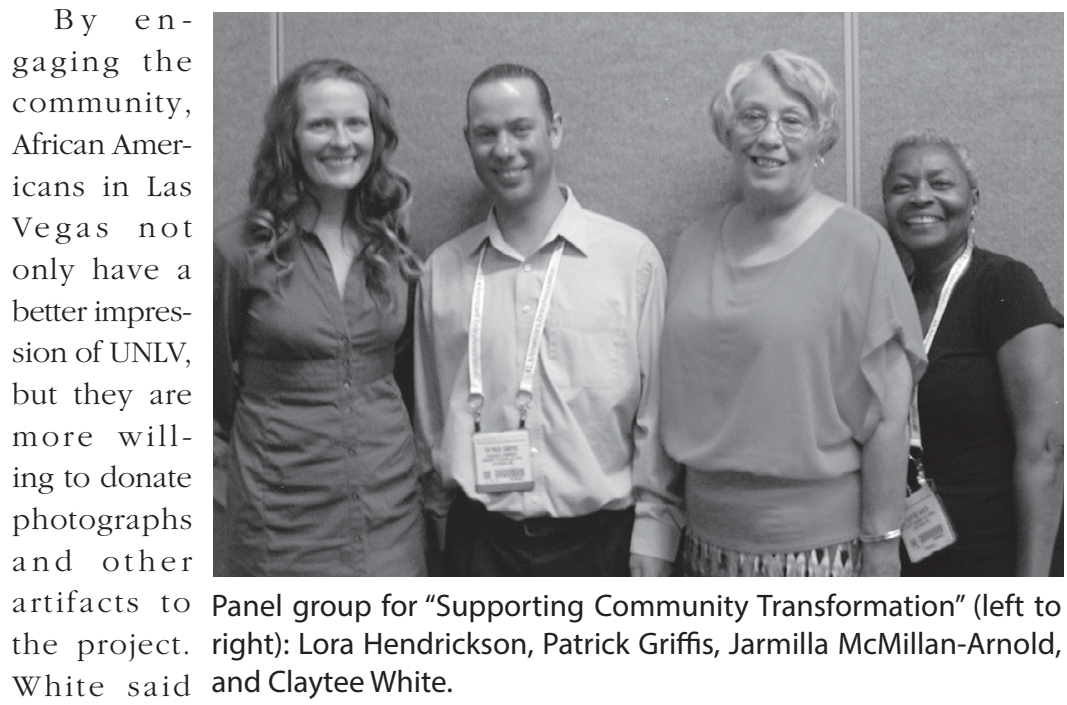

White said and Claytee White.

that her next

project will be about the Jewish experience in Las Vegas._Jodie Borgerding, Webster University, jborgerding80@webster.edu

\section{Science + Form $=$ Function}

Speakers Hannah Bennett, Kenneth Kornberg, and Michael Arbib with backgrounds in libraries, architecture, and neuroscience presented on the sensory experience libraries offer and the partnership between neuroscientists and architects in designing libraries to influence desired activities. Neuroscience measures the chemical and electrical responses to stimuli, architecture manages behavior through design, and experience can change the brain. Speakers asked the question: When designing space, do librarians need to know about the neuromechanisms that control reaction to environment? optimal functional design. What is the end result neurologically when functionality argues for a drivethrough window and call center model of libraries? What we have learned in neuroscience is that humans don't multitask, contrary to popular belief, leading to the conclusion that the library has place as a good long future as a result. For more information, visit www.anfarch.org-Cheryl McGrath, Stonehill College, cmcgrath1@ stonebill.edu

\section{Leading from the Side: On, Off, and Within Your Campus}

Leadership without official administrative authority formed the discussion for "Leading From the Side: On, Off, and Within Your Campus," featuring librarians Jade Winn (University of Southern California), Joseph Thomas (East Carolina University), and Kyle Denlinger (Wake Forest University). The panel was moderated by Carrie Moran (University of Central Florida) and sponsored by the University Libraries Section, the Distance 
Learning Section, and the Library Leadership and Management Association.

In response to questions from the moderator, the panelists discussed their view of leadership as team building, coordinating work to advance the goals of the library, and providing ideas and enthusiasm, which is often distinct from management. Regarding identifying partners for projects, Winn discussed forming partnerships through not only planning and assessment but also by casual conversations and being excited about projects. Thomas noted it is important to make sure partners are willing to commit time to a project, and Denlinger discussed attracting partners naturally by being a resource for others inside or outside the library. Panelists noted the importance of being flexible with technology and evaluating which tools will work best for given situations. Leaders need to communicate ideas and activities, and strategies presented by panelists included building relationships in which

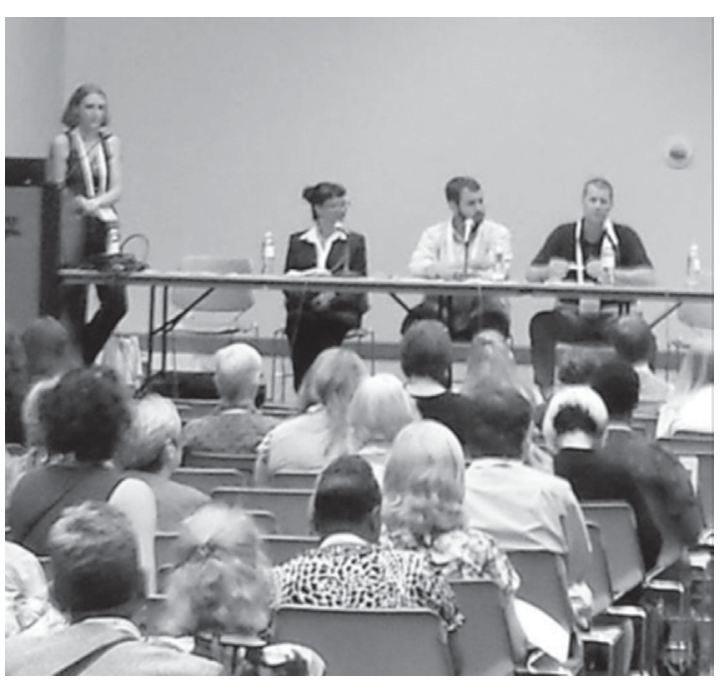

"Leading from the Side" panelists (left to right): Carrie Moran (University of Central Florida), Jade Winn (University of Southern California), Kyle Denlinger (Wake Forest University), and Joseph Thomas (East Carolina University). people are comfortable sharing ideas, and developing effective methods of communicating both formally and informally to make sure everyone is kept in the loop.

Without having formal administrative authority, getting buy-in from other departments can be challenging. Panelists' strategies included demonstrating how a project is beneficial for the group, library or campus; being realistic and honest about expectations from others; making sure all stakeholders needs are considered when making decisions; and trying to understand and accommodate multiple needs and goals. Denlinger recommended the StrengthsFinder assessment as a method of identifying each person's strengths, and then focusing on the strengths already available in groups instead of focusing on improving our weaknesses. Finally, the panelists discussed dealing with roadblocks or speed bumps and shared resources they follow. For more information, see http://connect.ala.org/ node/221096.-Britt Fagerheim, Utah State University, britt.fagerbeim@usu.edu

\section{Your academic library career and parenting}

Two academic librarians who are both coincidentally mothers of identical twins, Joyce Garczynski (Towson University) and Leahkim Gannett (University of California-Santa Barbara), presented "Are You Taking a Gamble on Your Academic Library Career by Having a Baby (or Two)?"

The program began with Gannett reviewing the literature on working parents in general, in academia, and in academic libraries. She noted that the research on academic librarian parents often contains small sample sizes and tends to focus on self-reported perceptions of the tenure process.

Because flexible work arrangements are considered key to keeping parents in the workforce, the speakers reviewed the language contained in library and university telework policies. Garczynski reported that almost half of the telework policies contain language suggesting that their institutions are not family-friendly and do not trust 
working parents. She then went onto argue that in order to change their policies, library employees need to change organizational culture and reframe the definition of diversity at their institutions. Garczynski presented three types of interventions-meaningful, conflict, and interactive-librarians can use to change their organization's culture towards working parents.

The presentation concluded with an audience-driven question and answer session focused on job interviews, parental leave, and additional research that needs to be conducted. The presenters plan on continuing their research and are considering their next project. Garczynski emphasized that there is a need for an ongoing support network for working parents in academic libraries and created a secret Facebook group to attempt to fill this void. Please contact Garczynski at jgarczynski@towson.edu if you are interested in joining this group.-Joyce Garczynski, Towson University, jgarczynski@towson.edu

\section{Research for action}

"A Crash Course in Evaluation Research," presented by Laura Saunders and Mary Wilkins Jordan (Simmons College Graduate School of Library and Information Science) offered participants an overview for setting up and executing a research study with special attention to surveys and focus groups. Saunders began the session by emphasizing that the purpose of research is to take action. We need to use data to inform decision making. She went on to explain the basic components of a research study, including defining the research question, identifying a population and sample, and choosing the methods for collecting data.

Wilkins Jordan then went into detail survey design, outlining the three steps to survey design as "identify your objectives, develop relevant questions, and test your instrument." She also discussed some of the common mistakes made in writing survey questions, such as ambiguous language, leading questions, and double-barreled questions, and offered some examples of each type of mistake and how to reframe each as a suitable survey question.

Saunders discussed the logistics of setting up and facilitating a focus group, including recruiting participants and designing questions. She recommended 7 to 15 participants per group, with about 4 to 6 questions for guiding the discussion. Some attendees asked whether librarians are qualified to run focus groups themselves, or whether they should hire an outside consultant. Saunders asserted that librarians can run their own focus groups, and suggested that by running their own groups they can probe more deeply into the ideas and questions that are most relevant to them.

The session wrapped up with the facilitators offering some advice on how to analyze results, including some basic statistics that could be applied to survey research, and a brief discussion of coding analysis for focus groups.-Laura Saunders, Simmons College, Laura,laura.lidano@simmons.edu

\section{Get writing!}

"Get Writing! Overcome Procrastination, Remove Roadblocks and Create a Map for Success" was a hands-on workshop in which about 130 library authors and wanna-be authors organized their writing projects and chose approaches and techniques to help them stick to a schedule.

First, participants identified a publication project they hoped to complete and worked together to make it SMART (Specific, Measurable, Attainable, Rewarding, Time-bound). Next they designed a workplan to facilitate completion of their project. Using a legalsize sheet of white paper and multicolored sticky notes, participants brainstormed the steps they'd need to accomplish in order to get their writing project done. They captured each step on a colored sticky note, using a pink one to identify steps that they thought would be especially difficult for them. They then grouped their steps into milestones and identified specific deadlines for each.

In the second half of the workshop participants learned and shared specific tech- 
niques to ensure that they would actually adhere to their schedule and complete their plan. Techniques included "Focusing on the Why," "Getting an Accountability Buddy," and "Creating Triggers" among many others. Each participant chose two motivation techniques and adapted it to fit his or her specific situation. Participants left the session with a structured work plan that included deadlines and techniques to help them successfully complete their writing project and get published.

A walk-through of this workshop, including the full list of the motivation techniques, is available at http://z.umn.edu/getpublished.Jon Jeffryes, University of Minnesota-Twin Cities, jon.jeffryes@gmail.com, and Jerilyn Veldof, University of Minnesota, jveldof@ umn.edu

\section{Collaborative publishing}

"Making Tenure: A Model for Collaborative Publishing," sponsored jointly by ACRL and the University Libraries Section, outlined a specific model to help academic librarians conduct team-based research and writing projects.

Angela Colmenares introduced the practical motivations for collaboration, including career drivers and division of labor. She described how collaborative articles often enjoy stronger research, more polished writing, and higher journal acceptance rates. She emphasized psychological payoffs of collaboration, including improved respect among colleagues, increased enjoyment of research, an enhanced workplace culture of teamwork, and a valuable mentoring opportunity.

Erin Dorris Cassidy described each step of research planning, data collection, analysis, and write-up. Although the principal investigator coordinates the team and keeps the project on track, the process is characterized by democratic decision-making and equal contributions, from task delegation for developing survey and research instruments, to group debate about the implications of collected data, to division of responsibility for writing manuscript sections and collective manuscript editing.
Cassidy shared "lessons learned" from five years of collaboration, ranging from careful selection of team size-three-to-four members was recommended-and the need for regular deadlines, to realistic expectations regarding a project's timeline and the benefits of varying team composition and team member roles between projects.

A clear consensus concerning authorship credit—for example, author byline order-is also essential.

Colmenares described favorite collaborative tools, including Doodle.com to coordinate numerous schedules, Google Docs, EndNote Web citation manager, and Microsoft Lync for virtual collaboration.

Audience members broke into groups and were given prompts to spark discussion of research topics, with the hope that everyone would leave the session with ideas to pursue and contacts for potential collaborators from other libraries.

The presentation slides, including contact information and additional sources, can be found at http://ala14.ala.org/node/14599.Erin Cassidy, Sam Houston State University, ecassidy@shsu.edu

\section{Tenure-track support systems}

ACRL sponsored "Tenure-Track Support Systems: Perceptions of Academic Librarians," presented by Molly Poremski and Amy Vilz (University at Buffalo). Tenure-track librarians face a significant learning curve in adjusting to new position responsibilities along with the responsibilities associated with tenure. Poremski and Vilz presented the results of their study of North American tenure-track librarians, which gaged what types of support structures are currently being offered by academic libraries, as well as levels of satisfaction with these structures.

The study defined support as release time, mentorship, and funds for professional development and research, and revealed acknowledgment by tenure-track librarians that institutional support mechanisms are valued, used, and expected by staff. One of the most salient findings presented was that 
survey participants overwhelmingly felt their MLS education did not prepare them to meet the requirements of tenure.

Additionally, availability of mentorship and the desire for tenure-track librarians to have a mentor were at interesting odds. According to the findings, mentors were not readily available, but a significant majority (80\%) of librarians agreed a mentor would be useful in the tenure process. Not surprisingly, the more professional development (travel) money the participant received, the higher the level of satisfaction. Overall, although uniformity exists in tenure criteria, the presentation showed inconsistent, unavailable, or inaccessible tenure support across academic libraries.

The survey, given in the fall of 2013, had a total of 302 tenure-track respondents, some of whom were in attendance. The audience included tenure-track librarians, library school students, and administrators charged with preparation of tenure dossiers. The discussion identified that there is high interest in what tenure support peers are afforded, issues of faculty librarians without tenure, using tenure support as a recruitment tool, and if the language of tenure support itself is problematic (such as "release time") as it implies a potentially spurious distinction between tenure and daily job duties.-Amy Vilz, University at Buffalo, amyvilz@buffalo. edu, and Molly Poremski, University at Buffalo, poremski@buffalo.edu

\section{Virtual reference with JoinMe}

John Burns (Dixie State University) presented on JoinMe, a powerful and simple online tool to aide librarians tasked with conducting quality virtual reference service. It allows the librarian to initiate a screen-sharing session with multiple participants via the Internet. Once connected, the session effectively enhances a traditional phone call with the ability to show and tell a patron whatever is needed.

The tool has three pricing models, one of which is free. Each price point was examined, and the speaker made the case that the free model is all that is needed in most virtual reference scenarios. The features of the tool were examined and described, namely the ability to share a screen, the ability to use VOIP or a phone call, the ability to invite multiple participants, the ability to show the viewers what is on the initiators screen while describing what is being seen, and the ability to use the JoinMe app on mobile devices.

Some questions arose as to what would need to happen to have the viewer become the person sharing the screen. Burns explained that the session would have to be restarted with the viewer acting as the initiator of the session. This feature represented the most significant downside to the free pricing model. Other questions centered on the features of the tool. Burns elaborated on all the features, particularly how it works, and he encouraged all participants to try JoinMe._John Burns, Dixie State University, burns@dixie.edu

\section{Threshold concepts}

Sponsored by the ACRL Instruction and Distance Learning Sections, "From Stumbling Blocks to Building Blocks: Using Threshold Concepts to Teach Information Literacy" was a timely exploration of threshold concepts for information literacy. As the penultimate draft of the new "Framework for Information Literacy for Higher Education" was discussed and debated in open meetings and in libraries around the country, this session became a chance for attendees to get some clarifications, good-natured provocations, and ideas for future use of threshold concepts.

Framing the session with some of the broad implications associated with using threshold concepts for information literacy, Lori Townsend (University of New Mexico) opened with some intriguing and provocative claims. As threshold concepts allow learners to try on a range of different conceptual lenses, this can address the power dynamics that privilege certain disciplinary perspectives over others, she asserted. Townsend also noted that although the direction that ACRL is going with the threshold concepts is valuable, as professionals, we are not beholden to following the letter of the law. The field 
will benefit from constant struggle with, and revisiting of, the new Framework.

The specter of change and change fatigue accompanied the enthusiasm for the new Framework. Korey Brunetti (City College of San Francisco) addressed the difficulty of moving from the procedural standards to a more conceptual approach that will be hard to accomplish in the traditional one-shot session. However, one upside is that threshold concepts move us towards a model that in Europe and the Americas: Challenges for Librarians." The program explored how libraries can work with ethnic cultural communities living within or dispersed among other, larger communities to preserve their languages, literatures, artistic traditions, cultural heritage, social identities, and often political autonomy.

The first speaker on the panel was Oksana Marafioti (author of American Gypsy and former BMI Kluge Fellow at the Black Mountain Institute, University of Nevada-Las Vegas),

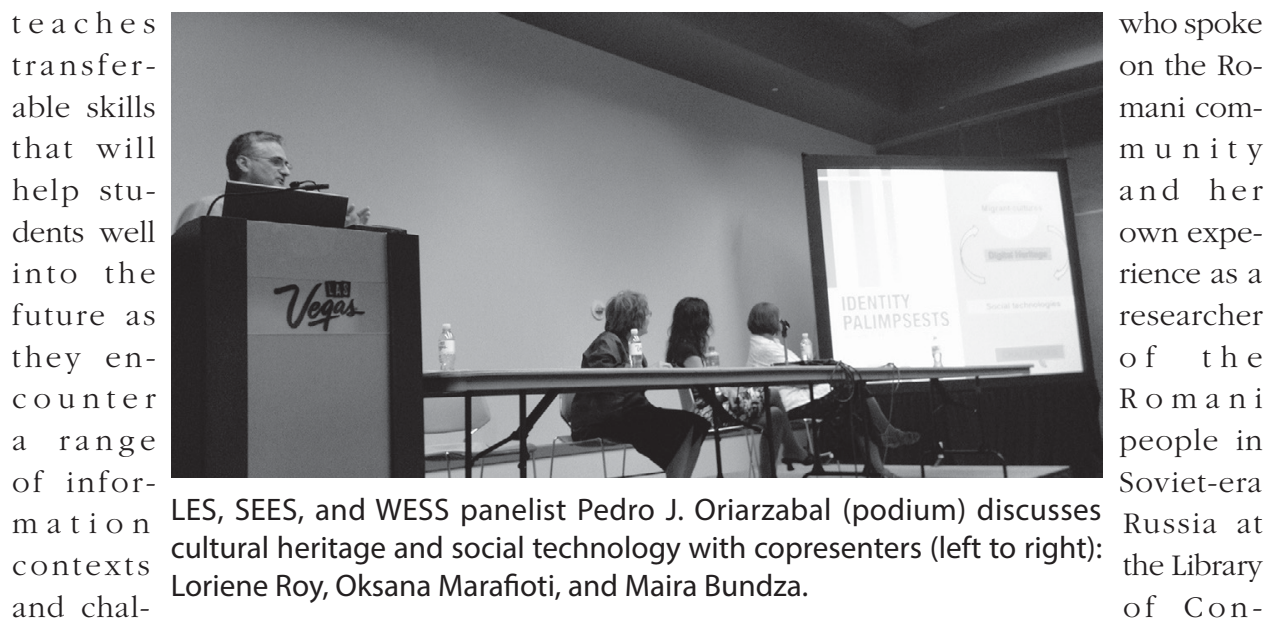

\section{lenges.}

How do we assess threshold concepts? Amy Hofe-r (Portland State University) urged the audience not to rush to standardize an approach, but to be reflective, proceed slowly with students and ourselves, and to spend time thinking about where students get stuck. "We are all co-investigators" as we begin to employ threshold concepts widely.

Lastly, the lightning talks focused on deconstructing databases, teaching reading skills as IL skills, and primary sources as contextually conditional.-Dave Ellenwood, University of Washington Bothell E Cascadia Community College, david.ellenwood@ gmail.com

\section{Cultural heritage and social technology}

The ACRL Literatures in English Section, Slavic and Eastern European Studies Section, and Western European Studies Section cosponsored "'Embedded' Cultural Communities gress. Libraries should seek out members of embedded cultural communities, she noted. Marafioti emphasized the importance of preserve the material of these embedded communities and we should not underestimate the interest in ethnic collections.

Pedro J. Oiarzabal (University of Deusto, Bilbao, Spain) next addressed the Basque diaspora in the Americas and the role of Internet and social media in creating community and saving their cultural heritage. Libraries and archives, he proposed, need to capture and preserve the "big data" of embedded cultural communities online. He reminded us librarians of the challenges in working with material created through social media.

The final panelist was Loriene Roy (School of Information at the University of Texas and former ALA president). She discussed her research on how libraries can help preserve Native American culture at both the small scale-local libraries reach- 
ing out to local Native populations-and the large scale with initiatives of larger, international groups. Roy gave an extensive overview of library projects in and around various Native American communities.

The session moderator and respondent was Maira Bundza (Western Michigan University), who brought her own experience documenting the Baltic American experience in libraries to bear upon the discussion.

During the discussion the panel urged the audience to look closely at their own ethnic collections and work with community members. Our bibliography is at http:// bit.ly/embedded_communities._Marcus Richter, Alma College, richtermj@alma. edu, and David D. Oberhelman, Oklahoma State University, d.oberhelman@okstate.edu

\section{Surveillance}

The ACRL Professional Values Committee sponsored a session entitled, "Surveillance." The featured speakers were Seeta Gangadharan (New America Foundation's Open Technology Institute) and Jim Teliha (ACRL liaison to the ALA Office of Intellectual Freedom and the Freedom to Read Institute).

Teliha kicked off the program by providing an overview of current laws as they relate to patron information and privacy, and discussing the principles underlying the ALA Code of Ethics and state privacy laws. Gangadharan followed and discussed her articulated four faces of surveillance, including mass surveillance, targeted government surveillance, targeted surveillance coupled with commercial data, and mass personalized data profiling.

Gangadharan also described her work with the Brooklyn (New York) Public Library in assisting to develop staff training on surveillance and privacy issues, so that staff can begin to develop a public education program. The session concluded with a lively and lengthy Q \& A session.-Theresa Liedtka, University of Tennessee-Chattanooga, Theresa-Liedtka@utc.edu

\section{Libraries in the publishing game}

While one role of the ACRL Publications COordinating Committee is to promote ACRL publishing venues, this year's panel "Libraries in the Publishing Game: New Roles from Content to Access" explored the work of three libraries developing innovative publishing programs around scholarship originating from their communities. Moderator Melinda Dermody (Syracuse University) introduced panelists to advise on setting goals, developing infrastructure, and marshalling library staff to take on new roles in preparing content for publication.

Rebecca Kennison (Center for Digital Research and Scholarship, Columbia University) observed that a true publishing program requires library participation in the editing and production process, presents original work not previously available, and applies some level of certification to the content published, whether that is peer review or simply institutional branding. Kennison supplied data from the Library Publishing Coalition's October 2013 Library Publishing Directory, demonstrating the breadth and impact of successful library publication programs.

Undergraduate and graduate student journals represent one emerging market for libraries to explore for publication, according to Catherine Mitchell (Access and Publishing Group at the California Digital Library [CDL], University of California). While they face challenges due to rotating staffing, inconsistent funding, or an unclear market, a well-managed program can engage editors to address staff turnover and knowledge transfer and anticipated costs in a sustainable way. CDL uses a rigorous proposal process and offers training to student editors around copyright and licensing via "self-serve" video tutorials and workshops.

"Thud factor," or the sound of a printed, library-created book hitting the desk of an impressed university administrator, was a key component in building support for SUNYGeneseo's publishing program, according to Library Director Cyril Oberlander. Between working with faculty to develop and review 
textbooks for the Open SUNY Textbook program and publishing work from their own faculty and special collections, they found ways to train librarians to take on copyediting and production roles in tandem with work ensuring discoverability. Their open access Library Publishing Toolkit summarizes advice for libraries considering a publishing program.-Priscilla Finley, University of Nevada-Las Vegas, priscilla.finley@unlv.edu

\section{Creating a successful residency program}

The Residency Interest Group sponsored the program "Stop Dreaming and Do It, Best Practices for Gaining Momentum, Developing and Maintaining a Successful Residen- programs. Advice was given on making a case with university administration and of the value that these programs provide to the library and the university as a whole. The residents offered an insider's perspective on applying to residencies and how to develop goals while within the program. The coordinators and the residents both offered advice on the best rotational structure of the residencies and the best practices regarding building a successful cohort.

The Q \& A session after the program sparked a conversation about the necessity of the on-campus interview for prospective residents, taking stock of the diversity of an area before committing to multiple residents, and the ways in which residencies have to cy Program" and brought together a range of panelists from three universities who began and work within a Diversity Residency Program.

This program described the creation of library diversity residency programs at three very different aca-

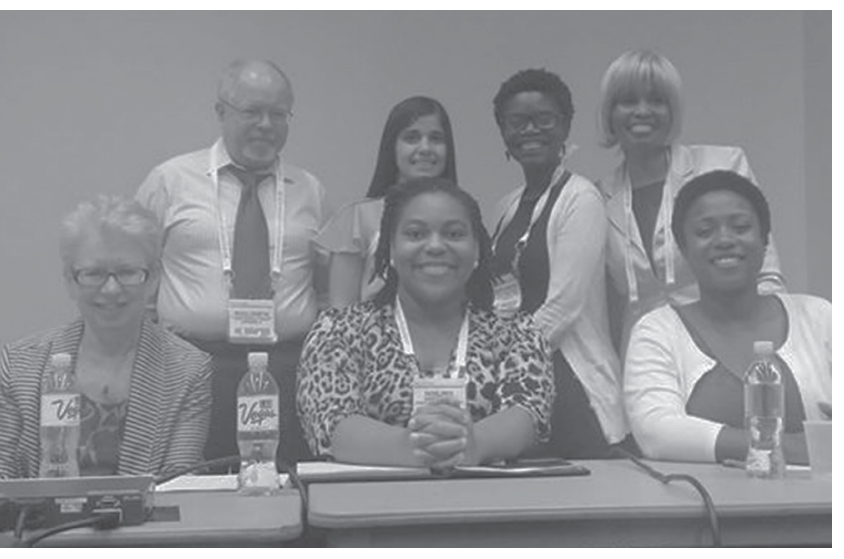

Residency Interest Group panelists from left to right (top): Michael Crumpton (University of North Carolina-Greensboro: Nataly Blas (Loyola Marymount University), Sojourna J. Cunningham (University of Tennessee-Knoxville), and Thura Mack (University of Tennessee- Knoxville). From left to right (bottom): Barbara Dewey (Penn State University), Rachel Smith (Penn State University), Ingrid Ruffin (University of TennesseeKnoxville).

demic librar-

ies. The panelists included Barbara Dewey and Rachel A. Smith (Penn State University); Michael Crumpton and Nataly Blas (University of North Carolina-Greensboro); and Thura Mack, Sojourna Cunningham, and Ingrid Ruffin (University of Tennessee-Knoxville).

The residency coordinators and deans spoke of their roles in not only building their residencies, but they also revealed what it takes to sustain the resources for their change to reflect the needs of an organization, i.e., rather than offering a broad choice of departments for residents to rotate in, offering a limited to choice to reflect the needs of an organization.Sojourna J. Cunningham, University of TennesseeKnoxville, scunni16@ utk.edu

\section{Sticking with STEM}

The Science and Technology Section's program, "Sticking with STEM: How the Academic Library Can Help to Retain Successful Students," was cosponsored by the Health Sciences Interest Group and in association with the Instruction Section. The first speaker, Joanna Jezierska (University of Nevada-Las Vegas) discussed UNLV's Multicultural Program 
for Engineering, Sciences, Allied Health Sciences, Community Health Sciences, and Nursing. The program seeks to recruit and retain minority and under-represented groups in STEM and healthcare-related fields. Outreach efforts focus on local, statewide networks from kindergarten through the sophomore year (K-20), including recruitment, transfer agreements, and internships. The program has support on all levels of the university's administration. UNLV librarians participate in outreach events and provide workshops and mentorship. UNLV had 230 students participating in 2013 and 348 in 2014.

Jan Fransen (University of Minnesota) discussed her library's data analyses to determine correlations between library use and GPA. The library collected data from the students that used the library, but they ensured that all privacy policies were followed as they conducted their analyses. They found that, in general, the students who used the library generally had higher GPAs. The library also collaborates with academic advising, which referred students to the library if they needed assistance with their assignments.

Carissa Tomlinson (Towson University) discussed several issues that affect student retention, including the social factors (fitting in); bureaucratic challenges, such as ease of registration, daycare, and parking; environmental challenges, such as jobs, family, relationships; and self-confidence and the drive to succeed. Tomlinson highlighted health profession majors, where students are trained to be practitioners and must show that they can practice what they have learned. The challenges for first-generation college students (or students from other cultures) include language barriers and cultural barriers (some cultures discourage direct eye contact). The role of their library includes connecting with the librarians in the "feeder" schools, participating in orientation programs, becoming involved with "College 101" programs, serving as mentors and offering office hours, and sponsoring peer mentoring.-Edward Kownslar, Texas
AEM University-Corpus Christi, Edward. Kownslar@tamucc.edu

\section{Digital humanities}

"Digital Humanities and Academic Libraries: Practice and Theory, Power and Privilege," sponsored by ACRL's Women and Gender Studies Section and Digital Humanities (DH) Interest Group, was a panel that explored the multiple roles librarians play in DH. Jane Nichols (Oregon State University) discussed her experiences designing and teaching an undergraduate DH course. She also reported on the ways a faculty survey at her institution has informed her thinking about a model for DH support. Roxanne Shirazi (The Graduate Center at CUNY and coeditor of $\mathrm{dh}+\mathrm{lib}$ ) placed DH work within the context of librarianship as a feminized profession, showing how concepts like shadow labor and emotion work help us think about why the contributions of librarians to $\mathrm{DH}$ projects are often rendered invisible. She argued that any discussion librarian/ faculty collaboration needs to include explicit conversations about working conditions and institutional structure.

Elvia Arroyo-Ramirez (Center for the Study of Political Graphics) talked about how recent "Exhibitions-to-Go" programs"Prison Nation: Posters on the Prison Industrial Complex" and "Boycott! The Art of Economic Activism"-are broadening the center's ability to reach beyond the traditional museum community. She raised several questions about the capacity of $\mathrm{DH}$ to engage political subject matter and the potential for $\mathrm{DH}$ as activism.

Megan Wacha (Barnard College) finished the panel by exploring some connections between DH, feminism, and technology, specifically looking at Wikipedia and Twitter as pedagogical tools. Highlighting her experiences as a Wikipedia author and as a librarian supporting a Wikipedia assignment in a literature course, she explored the gendered nature of online environments and argued that open access is a feminist endeavor.-Stacy Russo, Santa Ana College, russo_stacy@sac.edu n 